\title{
Pancreatic Neuroendocrine Tumor TNM Finding v8
}

National Cancer Institute

\section{Source}

National Cancer Institute. Pancreatic Neuroendocrine Tumor TNM Finding v8. NCI

Thesaurus. Code C135536.

A finding about one or more characteristics of a pancreatic neuroendocrine tumor, following the rules of the TNM AJCC V8 classification system. This classification system applies to well-differentiated neuroendocrine tumors arising in the pancreas. It does not apply to carcinomas of the pancreas, including high-grade (grade 3), poorly differentiated neuroendocrine carcinomas. (from AJCC 8th Ed.) 